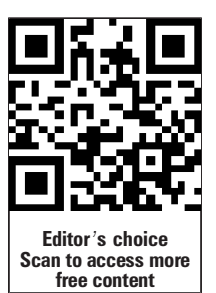

- Additional materials are published online only. To view these files please visit the journal online (http://dx.doi.org/ $10.1136 /$

emermed-2012-201341)

${ }^{1}$ Department of Public Health, School of Specialization in Public Health, University of Turin, Turin, Italy

${ }^{2}$ Health Service Organization, Rivoli Hospital, Rivoli (Turin), Italy

${ }^{3}$ Emergency Department, Rivoli Hospital, Rivoli (Turin), Italy ${ }^{4}$ Department of Public Health, University of Turin, Turin, Italy

\section{Correspondence to}

Dr Marika Giacometti, Department of Public Health, School of Specialization in Public Health, University of Turin, Via Santena 5/bis, Torino, Turin 10126, Italy;

marika.giacometti@unito.it

Accepted 10 June 2012

Published Online First 3 July 2012

\title{
Humanisation in the emergency department of an Italian hospital: new features and patient satisfaction
}

\author{
Emanuela Lovato, ${ }^{1}$ Davide Minniti, ${ }^{2}$ Marika Giacometti, ${ }^{1}$ Roberto Sacco, ${ }^{2}$ \\ Alberto Piolatto, ${ }^{3}$ Bruno Barberis, ${ }^{3}$ Riccardo Papalia, ${ }^{1}$ Fabrizio Bert, ${ }^{1}$ Roberta Siliquini ${ }^{4}$
}

\section{ABSTRACT}

Objectives The goal of this study was to describe and analyse interventions performed in the emergency department (ED) of an Italian hospital with the aim of humanising the patient care pathway. The actions taken are described and the changes analysed to determine whether they resulted in an increased level of patient satisfaction

Methods An observational study was conducted between October 2010 and March 2011. The data were collected via a telephone questionnaire administered to patients who were admitted to the ED before and after humanisation interventions. The respondents were questioned about their general condition and their level of satisfaction.

Results The study population included 297 patients (158 before and 139 after the interventions). The highest overall patient satisfaction after the interventions was highly correlated with the humanisation interventions and not with other factors such as gender, age, educational level or the severity code triage. Specifically, in patients who went to the ED after the changes had been made, there was a greater level of satisfaction regarding comfort in the waiting room, waiting time for the first visit and the privacy experienced during the triage.

Conclusion The results demonstrate that the interventions implemented in this study, designed to humanise the ED, improved overall patient satisfaction. Interventions may be taken to reduce the depersonalisation of patients in the emergency room.

\section{INTRODUCTION}

In recent years the levels of medical assistance and hospital care have been enhanced as a result of technological performance improvements in diagnostics and treatment. However, care pathway fragmentation, the increase in medical specialists and the lack (at least in Italy) of a 'care manager' have led to the depersonalisation of patients. These issues are greater in the emergency department (ED) due to the services provided and the greatest risk of depersonalisation or 'dehumanisation'. ${ }^{1}$

In the current global financial crisis, quality is a critical factor for the survival of healthcare facilities. Although every effort is aimed at reducing costs and increasing the number of procedures performed, the risk of losing the centrality of the patient as a 'human' is high.

Since the 1990s, research interest in clinical practice quality assessment has continuously grown. ${ }^{2} 3$ The concept of 'customer satisfaction' (or 'patient satisfaction') must be placed in the context of overall quality improvement, and it is a serious issue in emergency medicine, as shown in the literature ${ }^{4-8}$ which emphasises the difficulty of accurately measuring patient satisfaction because it may be influenced by perception, the interpretation of events or clinical conditions. ${ }^{1}$

Quality and satisfaction are strictly related to the concept of humanisation of healthcare, which involves medical services for diagnostics and treatment and also the other aspects of the care process such as logistics, environment, food, waiting times and communication. ${ }^{9}$ However, little attention has been given to the concept of 'humanisation' in international medical publications because the literature is more focused only on the concept of 'patient satisfaction'

Few studies have compared the level of satisfaction perceived by patients before and after an ED humanisation intervention, ${ }^{10} 11$ and most of the studies have focused on a specific intervention. For example, Kologlu et $a l^{12}$ and Krishel et a ${ }^{13}$ reported the results of an improvement intervention (ie, the distribution of an information form), Corbett et al studied an informational videotape ${ }^{14}$ and George et al used an informal prioritisation process for waiting times. ${ }^{15}$

Other studies have suggested that patients' overall perception of care appeared to be associated with the humanistic attitude and technical competencies of the professionals, the perceived waiting time, the perceived total time spent in the $\mathrm{ED}$ and the amount of information provided to patients. 71116 However, there are other factors associated with patient satisfaction that are difficult to evaluate, such as privacy, cleanliness, safety and low noise levels in patient rooms. ${ }^{4}$

Despite the high incidence of ED use, in Italy only a few examples of the humanisation process can be enumerated and most of these are associated with patients with a specific pathology. ${ }^{17} 18$

The aim of this paper is to describe and evaluate the effectiveness of interventions designed to improve the patient experience in the ED.

\section{METHODS}

An observational longitudinal before and after study was conducted to evaluate patient satisfaction levels ${ }^{19}$ after a series of structural and organisational changes were applied in an ED. The study was authorised by the Health Department staff and carried out from October 2010 to March 2011 in the ED of Rivoli Hospital located in the Turin urban area

\section{Study population}

The study population included all patients who were admitted to the emergency room during 
October, November and December 2010 (before the 'humanisation' interventions) as well as during January, February and March 2011 (after the 'humanisation' interventions). To select patients for this study we chose 2 days of the week and contacted all of the patients who had been admitted to the ED during those specific days. Saturday and Wednesday were chosen to represent the holidays and work days, respectively. Patients admitted with a triage 'Red Code' due to the admission details that characterised these patients, such as the urgency of their condition, were excluded.

\section{Study design}

Patients were contacted by telephone 2 weeks after visiting the ED. Participation in the interview, which was conducted by medical professionals, ${ }^{5} 20$ was voluntary after the patient was given a thorough explanation of the study and gave consent. Before the interview the patient was informed about the opportunity to refuse or stop the interview at any time. Clinical data on the patient's condition or information about prescribed therapies or diagnostics performed in the ED were not collected.

Ethical approval is not necessary in Italy for customer satisfaction surveys when this kind of study is conducted after authorisation by the hospital management and all the data are processed anonymously. The personal data of patients collected from the clinical record were therefore used only to identify the patients called, but were not inserted in the interview database in order to guarantee anonymity.

The questionnaire was first tested in a pilot study on 30 individuals who were excluded from the final study. The questionnaire was designed to measure overall patient satisfaction and to assess, at an individual level, the different aspects of satisfaction. We calculated the average satisfaction values for the abovementioned categories - namely, first impression of the ED, adequacy of signage, comfort level in the waiting room, presence and availability of staff, waiting time for the first visit, clarity of information received, volunteer activities, discretion during triage and overall opinion. Using a 10-point scale, the average values were calculated to assess the satisfaction trends before and after the intervention.

In addition, patient demographic information (age, sex and educational level) and other information (admission time to the $\mathrm{ED}$, triage code and previous ED admissions) were included.

The study population was then divided into two subgroups: the first group ('Before') included patients who were admitted to the ED before implementation of the changes described above and the second group ('After') consisted of those who went to the ED after the changes had been implemented. The inclusion criteria ensured the comparability of the groups.

In order to humanise the care pathway, we studied and performed structural and organisational changes to improve the $\mathrm{ED}$ area. The changes that were implemented are described in table 1.

A descriptive analysis of the study population, including patient demographic information (age, sex, and educational level) and other information (admission time to the ED, triage code, and previous ED admissions) was performed to verify the comparability of the two groups.

\section{Analysis of data}

Multinomial logistic regression was performed to identify the potential predictors of the differences in the distribution among the three classes of patient satisfaction (poor, medium and high). We developed several bivariate models and identified variables that were significantly associated with the outcome at a $5 \%$ level. These variables were included in the multinomial regression analysis. In the final model the variables were group, age class, gender and education. The final model estimates for each of the variables were adjusted by controlling for the other variables. A two-tailed $p$ value of 0.05 was considered significant for all analyses, which were carried out using Stata V.11.

\section{RESULTS}

The source population was made up of all persons attending the ED on the days established. It was necessary to exclude $52 \%$ of the subjects due to lack of contact information or because they did not answer the telephone on two occasions. The study population was composed of 576 individuals who were invited to participate in the interview. The compliance rate was $53 \%$. The final sample therefore comprised 297 subjects (49.5\% men) of mean \pm SD age $48.6 \pm 13.9$ years. The details and descriptive characteristics of the participants stratified by group ('Before' and 'After') are summarised in table 2.

We initially estimated the range of the average satisfaction level by group (figure 1). The perceived satisfaction level was slightly greater in the 'After' group for the following categories: comfort level in the waiting room, waiting time for the first visit, clarity of the information received, discretion during triage and overall opinion. In contrast, the overall average rating in the 'After' group was slightly lower for first impression of the ED, adequacy of signage and presence and availability of staff.

Table 1 Structural and organisational interventions

Introduction of a new triage 'silver code'

Review of criteria for paediatric triage

Create a new triage room with a dedicated nurse

Improvement of the waiting room

Creation of a waiting room specifically for paediatric patients

Introduction of volunteers
In Italy, a four-colour level triage system is used (in ascending emergency order: white, green, yellow and red). The 'silver code' is a priority green code assigned to elderly patients ( $>70$ years) with certain clinic characteristics to ensure shorter waiting times ${ }^{21} 22$ (see Annex 1 online only)

A multidisciplinary working group established new standards and pathways for paediatric triage to ensure paediatric patient care pathway uniformity, less resource utilisation and more rational pathways to meet the patient needs (see Annex 2 online only)

To accelerate and streamline triage operations, a new position, namely, a 'welcoming manager' with management and patient sorting skills, was defined.

The dedicated nurse is the professional reference for a patient and his/her family.

The waiting rooms were improved by renovating the design (or layout) of facility spaces and increasing the number of facilities ${ }^{23}$

A paediatric patient waiting room was furnished according to the needs of this age group

In the early stages of the project it was decided to define clearly the roles and assigned tasks of volunteers. Volunteer staff training was ensured by developing a course that was organised by the hospital 
Table 2 Description of study population $(\mathrm{N}=297)$

\begin{tabular}{lccc}
\hline & 'Before' group N (\%) & 'After' group N (\%) & p Value \\
\hline Gender & & & \\
Male & $75(47.5)$ & $72(51.8)$ & 0.45 \\
Female & $83(52.5)$ & $67(48.2)$ & \\
Mean (SD) age & $48.41(13.75)$ & $48.71(16.60)$ & 0.65 \\
Age group & & & \\
$16-45$ & $66(44.6)$ & $55(39.9)$ & 0.14 \\
$46-65$ & $67(45.3)$ & $58(42)$ & \\
$>66$ & $15(10.1)$ & $25(18.1)$ & \\
Education & & & \\
Primary & $31(19.6)$ & $17(12.6)$ & 0.06 \\
Middle school & $54(34.1)$ & $45(33.5)$ & \\
High school & $49(31.0)$ & $59(44.0)$ & \\
College graduate & $24(15.1)$ & $13(9.7)$ & \\
Triage code & & & \\
White & $10(7.4)$ & $8(8.0)$ & 0.73 \\
Green & $98(72.6)$ & $68(68)$ & \\
Yellow & $27(20.0)$ & $24(24.0)$ & \\
\hline Siver code &
\end{tabular}

Silver code introduced in the 'After' group and used in 10 patients.

In agreement with other studies, ${ }^{24}$ the individual scores were grouped into three levels:

- 'poor' satisfaction (grades 1-4)

- 'fair' satisfaction (grades 5-7)

- 'good' satisfaction (grades 8-10)

The relationship between the level of perceived patient satisfaction and the humanisation intervention is summarised in table 3 .

We considered the respondents' level of satisfaction for each category and compared the responses of the two groups. The satisfaction ratings of the two patient groups differed in the following categories: first impression of the ED $(p<0.001)$, adequacy of signage $(p=0.019)$, presence and availability of the staff $(p<0.001)$, waiting time for the first visit $(p<0.001)$, discretion during triage $(p=0.03)$ and overall opinion $(p<0.001)$.

Patients in the 'After' group showed greater satisfaction in the following categories: waiting time for the first visit, clarity of information received, discretion during triage and overall opinion of the ED. In contrast, the patients in the 'After' group appeared to perceive a lower satisfaction in the following categories: first impression of the ED, adequacy of signage, and presence and availability of the staff. Of the patients admitted before the structural and organisational changes were implemented, $60.1 \%$ reported a fair first impression of the ED and $32.3 \%$ had a good opinion. In the 'After' group, $67.6 \%$ had a fair opinion of the ED and only $9.4 \%$ had a good first impression of the $\operatorname{ED}(\mathrm{p}<0.001)$.

In the 'Before' group, $7.6 \%$ of patients had a negative opinion regarding the adequacy of the signage, and this percentage rose to $17.3 \%$ in the 'After' group $(p=0.019)$. Similar results were found for the presence and availability of the staff (fair/good evaluations given by $92.4 \%$ of patients in the 'Before' group and $87 \%$ of patients in the 'After' group; $p<0.001$ ). We did not find any statistical differences between the level of comfort in the waiting room $(p=0.46)$ and the clarity of information received $(\mathrm{p}=0.57)$.

We specifically analysed these data using a multivariate analysis to investigate which factors affected the overall patient opinion using overall good opinion as the dependent variable. Table 4 shows that the categories significantly associated with an overall good opinion of the ED $(p<0.05)$ were level of comfort in the waiting room, waiting time for the first visit and discretion during triage. All of these variables had a positive effect on patient satisfaction while the first impression of the ED had a negative effect.

A multinomial logistic regression was performed to identify the potential predictors of the differences in the score distributions among the three classes of patient satisfaction. Table 5 shows that the 'After' group had a greater level of satisfaction
Figure 1 Medium level of patient satisfaction before and after implementation of the changes in the emergency department.

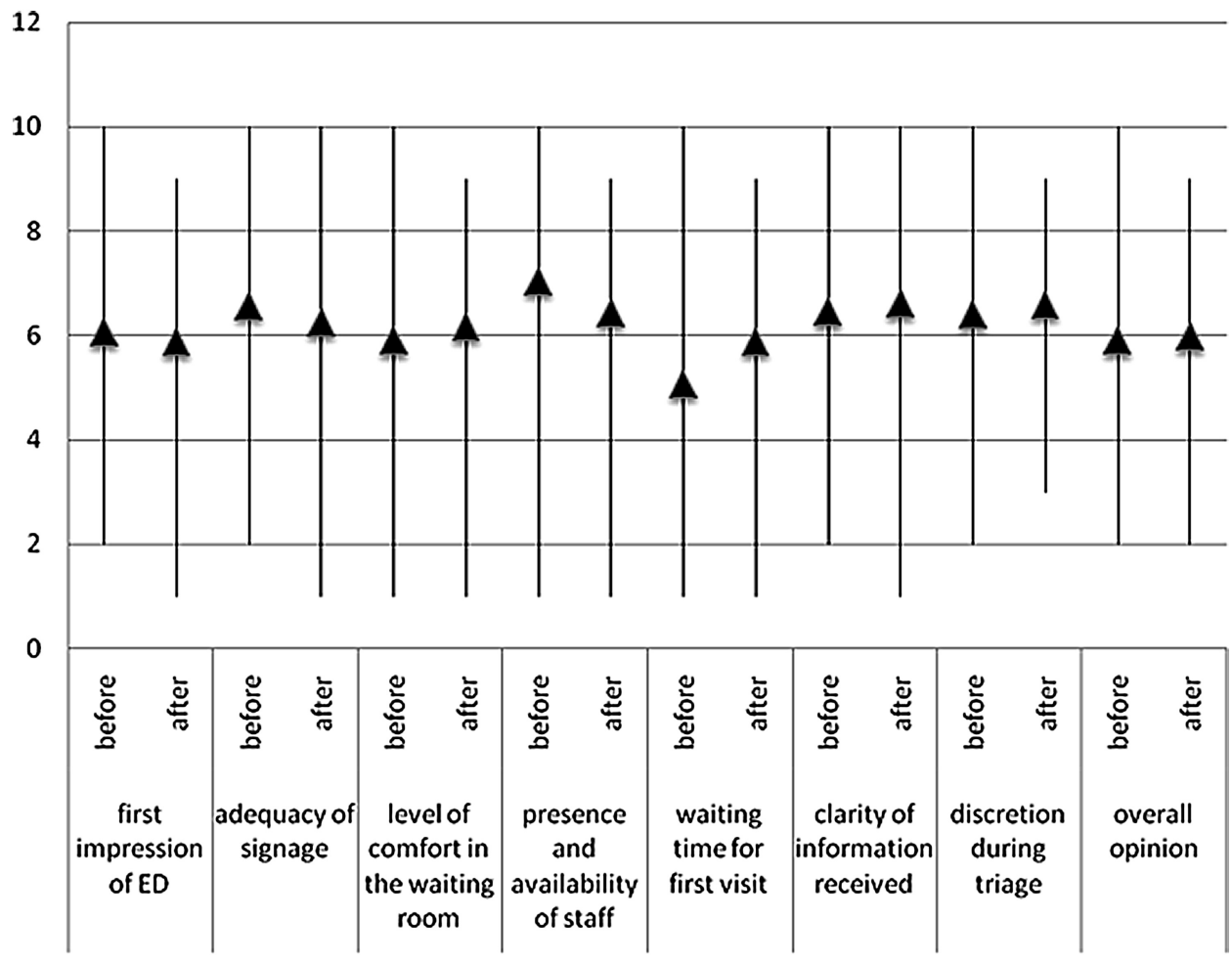


Table 3 Categories of patient satisfaction before and after the humanisation interventions

\begin{tabular}{|c|c|c|c|c|c|c|c|}
\hline & \multicolumn{3}{|c|}{ 'Before' group, N (\%) } & \multicolumn{3}{|c|}{ 'After' group, N (\%) } & \multirow[b]{2}{*}{ p Value } \\
\hline & Poor & Fair & Good & Poor & Fair & Good & \\
\hline First impression of the ED & $12(7.6)$ & $95(60.1)$ & $51(32.3)$ & $32(23.0)$ & $94(67.6)$ & $13(9.4)$ & $<0.001$ \\
\hline Adequacy of signage & $12(7.6)$ & $102(64.6)$ & $44(27.8)$ & $24(17.3)$ & $88(63.3)$ & $27(19.4)$ & 0.019 \\
\hline Level of comfort in the waiting room & $30(19)$ & $96(60.8)$ & $32(20.2)$ & $33(21.2)$ & $75(54)$ & $31(49.2)$ & 0.46 \\
\hline Presence and availability of staff & $12(7.6)$ & $73(46.2)$ & $73(46.2)$ & $18(13)$ & $90(64.7)$ & $31(22.3)$ & $<0.001$ \\
\hline Waiting time for first visit & $69(43.7)$ & $65(41.1)$ & $24(15.2)$ & $27(19.4)$ & $76(54.7)$ & $36(25.9)$ & $<0.001$ \\
\hline Clarity of information received & $19(12)$ & $102(64.6)$ & $37(23.4)$ & $16(11.5)$ & $83(59.7)$ & $40(28.8)$ & 0.57 \\
\hline Volunteer activities & - & - & - & $1(0.72)$ & $78(56.1)$ & $60(43.1)$ & \\
\hline Discretion during triage & $13(8.2)$ & $116(73.4)$ & $29(18.3)$ & $15(10.8)$ & $83(59.7)$ & $41(29.5)$ & 0.03 \\
\hline Overall opinion & $35(22.2)$ & $99(62.6)$ & $24(15.2)$ & $7(5)$ & $112(80.6)$ & $20(14.4)$ & $<0.001$ \\
\hline
\end{tabular}

than the 'Before' group regarding overall opinion of the ED. In particular, by comparing the overall opinion scores in the two groups, we found that the 'After' group had a higher probability of having an opinion of 'fair' (regression coefficient 1.50, $\mathrm{p}=0.001$ ) or 'good' (regression coefficient 1.17 and $\mathrm{p}=0.031$ ) compared with the probability of an overall opinion of 'poor' (table 5)

\section{DISCUSSION}

The results demonstrate that the interventions implemented in this study, designed to humanise the ED, improved overall patient satisfaction.

This is the first study conducted in Italy to describe a variety of significant structural and organisational changes implemented in the ED and to investigate how these changes are perceived by patients. The international literature is primarily focused on 'patient satisfaction', but a small number of recent studies have

Table 4 Satisfaction categories that determine high overall patient satisfaction

\begin{tabular}{|c|c|c|c|}
\hline & OR & p Value & $95 \% \mathrm{Cl}$ \\
\hline \multicolumn{4}{|c|}{ First impression of the ED } \\
\hline Poor & 1 & - & - \\
\hline Fair & 0.88 & 0.002 & 0.18 to 0.42 \\
\hline Good & 0.38 & 0.28 & 0.66 to 2.19 \\
\hline \multicolumn{4}{|c|}{ Adequacy of signage } \\
\hline Poor & 1 & - & - \\
\hline Fair & 1.13 & 0.88 & 0.21 to 6.02 \\
\hline Good & 0.67 & 0.68 & 0.09 to 4.71 \\
\hline \multicolumn{4}{|c|}{ Level of comfort in the waiting room } \\
\hline Poor & 1 & - & - \\
\hline Fair & 6.24 & 0.03 & 1.14 to 34.02 \\
\hline Good & 1.74 & 0.68 & 0.20 to 14.59 \\
\hline \multicolumn{4}{|c|}{ Presence and availability of staff } \\
\hline Poor & 1 & - & - \\
\hline Fair & 0.22 & 0.11 & 0.03 to 1.42 \\
\hline Good & 1.29 & 0.8 & 0.17 to 9.8 \\
\hline \multicolumn{4}{|c|}{ Waiting time for first visit } \\
\hline Poor & 1 & - & - \\
\hline Fair & 12.76 & 0.009 & 1.87 to 86.83 \\
\hline Good & 25.79 & 0.002 & 3.38 to 196.54 \\
\hline \multicolumn{4}{|c|}{ Clarity of information received } \\
\hline Poor & 1 & - & - \\
\hline Fair & 0.16 & 0.06 & 0.02 to 1.13 \\
\hline Good & 0.36 & 0.33 & 0.046 to 2.84 \\
\hline \multicolumn{4}{|c|}{ Discretion during triage } \\
\hline Poor & 1 & - & - \\
\hline Fair & 2.66 & 0.44 & 0.21 to 32.65 \\
\hline Good & 15.84 & 0.03 & 1.23 to 203.6 \\
\hline
\end{tabular}

described and studied structural and organisational changes in the ED. Moreover, these studies have referred to individual actions (ie, structural or organisational) ${ }^{13}$ and hardly investigated the level of satisfaction perceived by the users in relation to these action. ${ }^{14}$ The active approach of this study, which included a practice intervention, in combination with the evaluation of the consequences of the interventions is a major strength of this study.

To choose the best interventions in the emergency room we performed a literature review and identified the most critical areas for 'depersonalisation', patient satisfaction and hospital organisation. Based on other published studies, we performed this study in the ED.

In accordance with other publications, telephone interviews were performed in this study. ${ }^{20}$ During the waiting time in the $\mathrm{ED}$, responses could have been affected by the user's state of mind or their health condition, particularly if the patient was unable to have an unbiased perspective. However, the telephone

Table 5 Results of the multinomial logistic regression evaluating potential predictors of the overall opinion of the emergency department (ED) in the 'After' group (dependent variable: overall opinion)

\begin{tabular}{|c|c|c|c|}
\hline Overall opinion of the ED (scale) & $\begin{array}{l}\text { Regression } \\
\text { coefficient }\end{array}$ & $95 \% \mathrm{Cl}$ & p Value \\
\hline \multicolumn{4}{|l|}{ Fair versus poor satisfaction } \\
\hline 'After' group & 1.50 & 0.61 to 2.39 & 0.001 \\
\hline \multicolumn{4}{|l|}{ Age class } \\
\hline $16-45$ & - & - & - \\
\hline $46-65$ & 0.23 & -0.60 to 1.06 & 0.58 \\
\hline$>66$ & 1.22 & -0.41 to 2.85 & 0.14 \\
\hline Gender: male & 0.12 & -0.65 to 0.89 & 0.76 \\
\hline \multicolumn{4}{|l|}{ Education } \\
\hline Primary & - & - & - \\
\hline Middle school & 0.32 & -0.86 to 1.49 & 0.60 \\
\hline High school & 0.30 & -0.86 to 1.47 & 0.60 \\
\hline College graduate & 0.41 & -1.02 to 1.83 & 0.57 \\
\hline \multicolumn{4}{|l|}{ Good versus poor satisfaction } \\
\hline 'After' group & 1.17 & 0.11 to 2.23 & 0.03 \\
\hline \multicolumn{4}{|l|}{ Age class } \\
\hline $16-45$ & - & - & - \\
\hline $46-65$ & 0.23 & -0.80 to 1.26 & 0.66 \\
\hline$>66$ & 0.42 & -1.52 to 2.36 & 0.67 \\
\hline Gender: male & 0.94 & -0.02 to 1.90 & 0.06 \\
\hline \multicolumn{4}{|l|}{ Education } \\
\hline Primary & - & - & - \\
\hline Middle school & 0.04 & -1.38 to 1.46 & 0.95 \\
\hline High school & -0.43 & -1.88 to 1.01 & 0.56 \\
\hline College graduate & 0.22 & -1.49 to 1.94 & 0.80 \\
\hline
\end{tabular}


survey method resulted in a lower response rate than face-toface interviews but a higher rate than email interviews. ${ }^{5}$

The main result of this study is an increased level of overall satisfaction after the changes in the ED. The elements found to affect overall patient satisfaction most were the level of comfort in the waiting room, waiting time for the first visit and discretion during triage. In agreement with other studies, we found that the perceived waiting time is a significant factor in satisfaction. ${ }^{5}$ Previous studies showed that patients who receive information concerning their medical care and the reasons for waiting reported much higher levels of satisfaction than others who do not receive this information. ${ }^{16}$ The findings of the present study demonstrate that discretion during triage is important in patient satisfaction, but not the clarity of information received.

We found a statistically significant decrease in the level of satisfaction from the 'Before' group to the 'After' group with regard to the first impression of the $\mathrm{ED}(\mathrm{p}<0.001)$, the adequacy of signage $(p=0.019)$ and the presence and availability of staff $(p<0.001)$. The first impression of the ED and adequacy of signage can be explained by considering that the interventions mentioned in this paper are part of the overall hospital restructuring. Therefore, the 'After' group visited the hospital when different areas were incomplete or undergoing construction.

With regard to the presence and availability of staff, it may be appropriate to separate 'presence' from 'availability' in any related analyses because the 'presence/number of workers' is an objective parameter whereas the 'availability' is a personal assessment. This result should therefore be reassessed with a larger study population and a greater number of observation days.

It is clear from these results that the availability of staff and communication are two key aspects for the patient. For this reason, future efforts to improve the patient experience in the ED should provide training for staff to improve the communication and management of human relationships.

Some weaknesses of the study have been identified. In particular, the actual waiting time for each patient, the reason for patient admission ${ }^{8}$ and the presence of pain were not evaluated. This information may affect the patient satisfaction level, as reported by other authors. ${ }^{10}$ Further limitations of the study are the small sample size and the lack of staff training programmes concerning the 'humanisation' concept.

We conclude that, for the first time, our study demonstrates that interventions designed to humanise the ED have a real and measurable effectiveness and increase overall patient satisfaction.

Contributors EL: analysis and interpretation of the data/drafting of the manuscript. DM: study concept and design/critical revision of the manuscript for important intellectual content. MG: analysis and interpretation of the data/drafting of the manuscript. RS: administrative, technical, or material support/study supervision. AP. administrative, technical or material support/study supervision. BB: administrative, technical or material support/study supervision. RP: acquisition of the data. FB: statistical expertise. RS: study concept and design/critical revision of the manuscript for important intellectual content.

Competing interests None

Patient consent Consent was obtained during telephone interview.
Ethics approval Ethics approval was provided by Health Department staff.

Provenance and peer review Not commissioned; externally peer reviewed.

\section{REFERENCES}

1. Mack JL, File KM, Horwitz JE, et al. The effect of urgency on patient satisfaction and future emergency department choice. Health Care Manage Rev 1995;20:7-15

2. Carpenter CR, Heard K, Wilber S, et al: Society for Academic Emergency Medicine (SAEM) Geriatric Task Force. Research priorities for high-quality geriatric emergency care: medication management, screening, and prevention and functional assessment. Acad Emerg Med 2011:18:644-54.

3. Pines JM, Asplin BR; Systems Approach Conference Panelists. Conference Proceedings: Improving the quality and efficiency of emergency care across the continuum: a systems approach. Acad Emerg Med 2011;18:655-61.

4. Welch SJ. Twenty years of patient satisfaction research applied to the emergency department: a qualitative review. Am J Med Qual 2010;25:64-72.

5. Trout A, Magnusson AR, Hedges JR. Patient satisfaction investigations and the emergency department: what does the literature say? Acad Emerg Med 2000; 7:695-709.

6. Thompson DA, Yarnold PR, Williams DR, et al. Effects of actual waiting time perceived waiting time, information delivery, and expressive quality on patient satisfaction in the emergency department. Ann Emerg Med 1996;28:657-65.

7. Thompson DA, Yarnold PR, Adams SL, et al. How accurate are waiting time perceptions of patients in the emergency department? Ann Emerg Med 1996:28:652-6.

8. Topacoglu H, Karcioglu 0, Ozucelik N, et al. Analysis of factors affecting satisfaction in the emergency department: a survey of 1019 patients. Adv Ther 2004;21:380-8.

9. Booth AJ, Harrison CJ, Gardener GJ, et al. Waiting times and patient satisfaction in the accident and emergency department. Arch Emerg Med 1992:9:162-8.

10. Soleimanpour H, Gholipouri C, Salarilak S, et al. Emergency department patient satisfaction survey in Imam Reza Hospital, Tabriz, Iran. Int J Emerg Med 2011;4:2.

11. Tran TP, Schutte WP, Muelleman RL, et al. Provision of clinically based information improves patients' perceived length of stay and satisfaction with EP. Am J Emerg Med 2002;20:506-9.

12. Kologlu M, Agalar F, Cakmakci M. Emergency department information: does it affect patients' perception and satisfaction about the care given in an emergency department? Eur J Emerg Med 1999:6:245-8.

13. Krishel S, Baraff LJ. Effect of emergency department information on patient satisfaction. Ann Emerg Med 1993;22:568-72.

14. Corbett SW, White PD, Wittlake WA. Benefits of an informational videotape for emergency department patients. Am J Emerg Med 2000;18:67-71.

15. George S, Read S, Westlake $L$, et al. Evaluation of nurse triage in a British acciden and emergency department. BMJ 1992;304:876-8.

16. Björvell $\mathbf{H}$, Stieg J. Patients' perceptions of the health care received in an emergency department. Ann Emerg Med 1991;20:734-8.

17. Ciprandi G, Incorvaia C, Scurati S, et al. Patient-related factors in rhinitis and asthma: the satisfaction with allergy treatment survey. Curr Med Res Opin 2011:27:1005-11.

18. Boccanelli A. The hospital of tomorrow: between humanization and cost restraints The case of cardiovascular diseases (In Italian). G Ital Cardiol (Rome) 2011:12:19-20.

19. McCarthy ML, Ding R, Zeger SL, et al. A randomized controlled trial of the effect of service delivery information on patient satisfaction in an emergency department fas track. Acad Emerg Med 2011;18:674-85.

20. Bursch B, Beezy J, Shaw R. Emergency department satisfaction: what matters most? Ann Emerg Med 1993;22:586-91.

21. Di Bari M, Balzi D, Roberts AT, et al. Prognostic stratification of older persons based on simple administrative data: development and validation of the "Silver Code," to be used in emergency department triage. J Gerontol A Biol Sci Med Sci 2010;65:159-64.

22. Storm-Versloot MN, Ubbink DT, Kappelhof J, et al. Comparison of an informally structured triage system, the emergency severity index, and the Manchester triage system to distinguish patient priority in the emergency department. Acad Emerg Med 2011;18:822-9.

23. Papa L, Seaberg DC, Rees E, et al. Does a waiting room video about what to expect during an emergency department visit improve patient satisfaction? CJEM 2008; 10:347-54

24. Bruce TA, Bowman JM, Brown ST. Factors that influence patient satisfaction in the emergency department. J Nurs Care Qual 1998;13:31-7. 